\title{
THE IMPORTASNCE OF MICROTEACHING WITH THE USE OF MULTIMEDIA BY STUDENTS OF THE DEMOCRITUS UNIVERSITY OF THRACE, GREECE.
}

\author{
Dr. Alexandros Papanis \\ Instructor of English Technical Terminology, School of Polytechnics, Democritus University of \\ Thrace, Xanthi - Greece.
}

DOI: 10.46609/IJSSER.2020.v05i10.004 URL: https://doi.org/10.46609/IJSSER.2020.v05i10.004

\begin{abstract}
The basic goal for the conduction of Microteaching lessons with the use of Multimedia by Greek university students in the Polytechnic School of the Democritus University of Thrace, Greece was to combine difficult technical theory and electrical engineering terminology in the English language with certain practical activities, tasks and exercises in such an effective and innovating way, so that students would easily become acquainted with ambiguous notions and ideas concerning their field of study on one side and the parallel application of essential pedagogical and teaching skills on the other. For instance, students were challenged to get familiar with the procedure for preparing a lesson plan on photovoltaic applications successfully, to select and define their teaching goals, to use suitable teaching means, to record and apply various teaching styles, and finally to implement the most appropriate teaching techniques. This way, Microteaching proved to be a suitable research field for the embodiment of good practices, constituting thus a useful pedagogic and teaching method as well as beneficial (self) evaluation tool. Furthermore, it was found that the utilization of new technologies facilitated the process of critical teaching analysis along with the self-assessment of intern students. During their work, students were separated in groups of five (5) people, thus assuring the largest possible interaction and interrelation, given the fact that they visited together various educational online portals, exchanged emails and messages, participated in discussion groups through skype, viberorzoom, shared responsibilities and acted, eventually, in close collaboration. Each individual voice was utilized within the group and a specific role was given to each member separately contributing with their own experiences to the final outcome. Through the constructive combination of multimedia and team-work, it was found that maximum educational benefits were achieved - a fact that constituted the fundamental goal of this work.
\end{abstract}

Keywords: Microteaching, English Technical Terminology, Digital Learning Environment and 


\section{International Journal of Social Science and Economic Research}

ISSN: $2455-8834$

Volume:05, Issue:10 "October 2020"

Technologies, Groups, Multimedia, Collaboration.

\section{The Microteaching Process}

Microteaching is a lesson micrography referring to the organization of a teaching module or activity and demands an analytic, structured and careful planning.

In reality, Microteaching constitutes a simulation technique through which a desirable form of education behavior on behalf of the students is possible to be achieved (Oikonomou, 2002).

In the present case, the chosen subject of Microteaching was on Solar Panels within the context of the English Technical Terminology Module, of the $1^{\text {st }}$ Semester of the Department of Electrical Engineering of the Polytechnic School of Xanthi of the Democritus University of Thrace, Greece.

The organization of the Microteaching was based on the conduction of a micro lesson having as basic characteristics the following three stages: 1. preparation (design), 2. implementation (effectuation) and 3. evaluation.

1. For the preparation stage, a lesson plan was drawn in a structured and disciplined way so as to fully correspond to teaching needs and demands of students.

During the Microteaching planning stage the proper selection and conceptualization of teaching goals, the use of effective means (traditional or contemporary), the implementation of specific teaching types and styles (frontal, interrogative, experimental, partnerial, group, etc.)consisted some of the basic parameters along with the use of proper techniques such as, for instance, asking questions, constructively conducting conversations in the English language, solving problems, planning activities, brainstorming, case studies etc. (Papanis, 2017).

2. During the Microteaching implementation stage, intern students were asked to complete a small-duration teaching lesson over a small group of students (usually up to five people) following a simplified but strictly controlled procedure and within strict time margins (usually within 15 or 20 minutes).

Through the specific Microteaching it was pursued to illuminate the main points of a highly specialized technical text concerning the use of solar panels in modern houses, despite the fact that the text included abstract notions or special information which demanded specific technical knowledge.

Students were also required to focus their attention on any important piece of information of the 


\section{International Journal of Social Science and Economic Research}

ISSN: $2455-8834$

Volume:05, Issue:10 "October 2020"

written text and analyze it comprehensively, so as to understand the direct and indirect (hidden) notions included in it, always through the use of a non-native language (English).

Additionally, students that participated in the Microteaching practiced in conversing fluently and with immediacy, making the conversation with the other students natural and unobstructedly, expressing opinions and developing arguments for the advantages or any potential disadvantages of the use of solar panels.

Finally, the stage of evaluation included critical analysis on the effectiveness of Microteaching in terms of the appropriate feedback provision concerning: 1) the Microteaching's organization, 2) the degree of the students' realization of the various complex technical notions and ideas, 3) the successful (or not) content presentation, 4) the range of the quality of the exercises, tasks and the activities selected and finally, 5) the proper (or not) time management.

Invaluable guiding role played the supervisor as well (in the specific case the author of this assignment and Teacher of English Technical Terminology in the Polytechnic School of Xanthi), who - in a climate of safety - evaluated the whole process, provided instructions and advice, reminded of the initial goals, ascertained the degree of their fulfillment and finally summarized and recapitulated the final conclusions.

\section{Microteaching through the use of Multimedia.}

Nowadays, the new technologies constitute an indispensable part of the Greek Higher Education and can be used for the effective combination of English Technical Terminology teaching with respective hypermedia, multimedia and the Internet.

At the premises of the Polytechnic School in Xanthi - Greece the average university student possesses a wide gamut of computational applications and electronic tools of language technology making thus the acquisition of English technical terminology a relatively easy and extremely interesting task.

For the successful accomplishment of both the general aim and the individual targets of the specific Microteaching the effort to enrich the presentation on solar panels with images, sound, video as well as with a maquette (scale model) presentation constructed by the participant students themselves was a particular challenge to them. Nevertheless, they acquired a first-hand experience of how to be active in a completely communicative environment by making use of various tools and applications, such as sending emails for the exchange of opinions regarding the Microteaching structure, its objectives, its proper lay out etc. Furthermore, extensive surfing on the Internet was held out for searching, tracing and retrieving the most relevant pieces of 
International Journal of Social Science and Economic Research

ISSN: 2455-8834

Volume:05, Issue:10 "October 2020"

information concerning practical problems such as the installation procedure of solar panels. In addition, other contemporary means of communication such as skype, zoom and viber were widely used for the purposes of setting up useful activities, reading comprehension questions, tasks and exercises.

\section{Microteaching through Group formation}

According to sociologist MartinBuber, people become "I" through "You" and the individual becomes -anthropologically speaking - an existing human being through a plethora of relationships and interactions with other individuals within the frame of a group, of a community or within society itself.

Similarly, students become a group when, based on their common experiences, they start developing mutual social relationships among them aiming at the fulfillment of their common educational goals and targets. In other words, through the students' active collaboration emerge the so called group dynamics.

For the purposes of the specific Microteaching the fundamental factors for the group formation by the participating students of the Department of Electrical Engineers inXanthi, Greece were three (3):

1. group size

2. group structure and

3. role of each member separately.

In order to obtain the maximum team flexibility it was decided that the group should be consisted ideally of five students who have already worked together in the past in one of the Greek speaking modules of the Department of Electrical Engineering, having thus already established close academic relationships among them.

Through group formation, the below goals were pursued:

1. Make use of all different voices since each member has its own particular experiences. Initial reservations regarding the difficulties to work together due to different feelings, mentalities and ways of thinking were eventually lifted under the acceptance that all voices are real and useful and, under no circumstances, are they homogenized.

2. Understand that internal dialogue developed in each role helps the emerging of not only apparent but also of latent (hidden) sides.

3. Highlight the need of clear presentation of the basic elements and parameters that emerged 


\section{International Journal of Social Science and Economic Research}

ISSN: $2455-8834$

Volume:05, Issue:10 "October 2020"

from the role assumption within the group context and reflection of the entire experience.

4. Document the findings - emotions and potential questions in the form of constructive feedback of the entire teaching process.

5. Underline the central questioning in the plenary session of participating students and

6. Complete the co-production of knowledge.

\section{Results and Discussion}

In general speaking terms, through Microteaching the effectuation of specific teaching goals was achieved ;feedback was facilitated along with the constructive evaluation and self-evaluation of the participants. Furthermore, certain teaching skills were promoted and new educational approaches were applied in the entire teaching process.

Students were asked to respond, during Microteaching, in collective and creative activities such as role-playing, brainstorming, group talks, action plans(group collaborative learning) etc. The most outstanding accomplishment however was the fruitful cultivation of the ability to "learn how to learn" (meta cognition) - in other words the students' ability to draw knowledge from every single source - educational or not - they come across in their daily life, such as dictionaries, internet, software, newspapers, magazines, professional manuals etc.

Furthermore, students' participation in group talks and work groups provided them with the opportunity to profoundly possess the subject of solar panels and effectively proceed to its comprehensive analysis.

On his behalf, the supervisor encouraged the students to use the Internet as a kind of a virtual library where- through coordinated visits in authentic sources of information such as news papers, magazines and brochures of various companies concerning the installation of solar panels - the participant students could critically explore the Internet, evaluate the results of their search, assess and categorize them. In essence, this constitutes a new form of electronic literacy, which the new generation is undoubtedly more familiar with.

Therefore, through the combination of 1.the research process, 2. The experiential learning, 3. The use of authentic material, 4. The interaction among the students and mostly 5. the detachment from a unique source of information to a much wider range of sources students were able to design an integrated and overall harmonic form of Microteaching and to present it to their fellow students who undertook the role of students. 
International Journal of Social Science and Economic Research

ISSN: 2455-8834

Volume:05, Issue:10 "October 2020"

Certainly, such an important effort could not remain entirely cloudless and without obstacles such as, for instance, overloaded Internet, slow connectivity or the inevitable confusion of students when in touch with a huge plethora of information offered by the Internet.

The last but not less important element to be mentioned was the students' effort to make the lesson pleasant and creative. After all, Microteaching must be joyful and interesting for teachers as well as for students.

Until the end of the specific teaching process, it is certain that both sides (students and the supervisor/teacher) have acquired mutual benefits: the students the new language skills to be developed and the supervisor the new cognitive fields of use of the foreign language to be approached exclusively through the experiences and the interests of students.

\section{Acknowledgments}

The author of this article would like to express his special thanks to his university students of the Department of Electrical and Computing Engineering George Tsismanidis, Helen Harizani and Stergios Karanatsios for their successful Microteaching Lesson they presented to their classmates and for all the equipment they constructed by themselves in order to support their Teaching effectively and under immense time pressure!

\section{References}

1. Kedraka, K. (2015). Microteaching as a Training Tool for Future Teachers: Opinions of Students of the Department of Molecular Biology and Genetics of the Democritus University of Thrace.

2. In the honors volume to Professor Emeritus D. Hatzidimou: Studies and Questions of Pedagogical Science, (ed. K. Bikos and E. Taratori), 227 - 246. Thessaloniki: Kyriakidis Bros. Publications SA.

3. Economou, N. (2002). ICT and language teaching: historical background, necessity and perspectives. Educational Issues Review, 9, 172-187.

4. Papanis, A. (2017) The purposes of micro-teaching, (retrieved on 22 - 8-2018 from the website https://agiasion.blogspot.com).

5. Buber, M (1923). I and Thou, Buber, M (1923). I and Thou, Copyrighted Material, Martino Publishing (2010). 
International Journal of Social Science and Economic Research

ISSN: 2455-8834

Volume:05, Issue:10 "October 2020"

\section{Some words about me:}

Alexandros Papanis graduated from the University of Athens, Department of English Language and Literature. His Master's Degree took place at the University of Nottingham, England. In 2008 he received his Doctorate $(\mathrm{PhD})$ from the Department of Preschool Education of the Democritus University of Thrace, Greece. The thesis of his $\mathrm{PhD}$ dissertation was on the English language learning strategies of Muslim students in Thrace. He has also graduated from the Hellenic Open University, Department of Business Administration (BA).

Currently, he is a permanent Lecturer of English Technical Terminology at the Polytechnic School of Xanthi, Democritus University of Thrace.

He has participated in many International Conferences as a lecturer on English Language Teaching, while his articles have been published in many scientific journals and newspapers.

\section{APPENDIX}

\section{The Students' Microteaching Lesson}

Hello ladies and gentlemen,

I am George Tsismanidis and these are my fellow students, Helen Harizani and StergiosKaranatsios. We are currently studying at the Department of Electrical and Computer Engineering, School of Polytechnics in Xanthi. During the first semester of our studies, we prepared and presented to our classmates a project in the form of a Microteaching under the general topic: "Solar panels and Energy". The presentation was supervised by our Professor of Technical English Terminology at the School of Polytechnics, Dr. AlexandrosPapanis.

You might already be acquainted with the model of Microteaching so far. It is an innovative teacher training method, which aims at helping both teachers and students discover the multidimensional aspects of Teaching in a more efficient way. Our overall goal was to present a specialized technical subject, such as Solar Panels, in a way that would be both comprehendible and pleasant to our classmates who undertook the role of being our students.

But why choose Solar Panels for our presentation? We strongly believed that - under the scope of the current environmental problems of our planet - all renewable sources such as sunlight, tides, geothermic energy, wind power etc., consist the ultimate solution in the field of energy production and we were therefore certain that our classmates would be pleased to get familiar with the alternatives of how to harness solar energy in an effective way.

As a start, we had to set out some of our major objectives: simplicity was one of them! 
Consequently, we removed all "unnecessary" details, like abstract terms or obscure and difficult to understand terminology, which required expert technical knowledge and which would, probably, confuse our fellow students. After all, how could it possibly be of any importance the effort to explain the complicated procedure that takes place when light falls upon the nonreflective glass at the top of the panel? The main idea to comprehend though was that when distinct particles of light, called photons, get absorbed by semiconductor materials like silicon, it is generated electricity due to the photovoltaic effect.

After having some basic terms explained, we had to make sure that our second objective, that is, keeping our Microteaching interesting and coherent, would be successfully achieved. We believe that we accomplished that mainly by adding images. For example, it seemed pointless to consume all our limited time (our Microteaching lasted for only twenty minutes) trying to present the numerous applications of solar panels, instead of showing these applications to them in the most vivid and descriptive way!

\section{Picture 1: How a Solar Panel works}
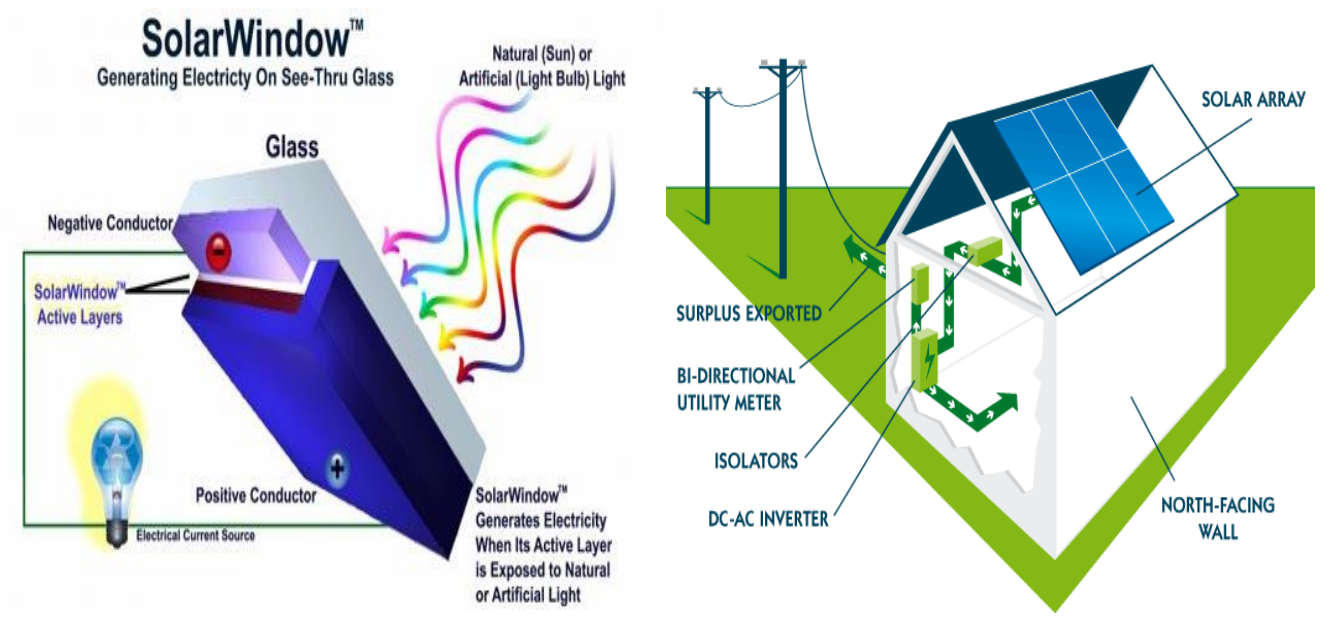

Source: Select energy, Power your Tomorrow

Finally, we urged students for a constructive discussion on the utility of the solar panels nowadays along with the benefits that solar panels might offer to the sustainability of the environment.

Once we had our objectives set, our next step was to choose the most suitable means of instruction. PowerPoint and Computers, videos, the various Internet facilities and the use of authentic sources like encyclopedias, books on solar panels and updated brochures of some of the most notorious companies which are pioneers in the specific field of interest helped us 


\section{International Journal of Social Science and Economic Research}

ISSN: 2455-8834

Volume:05, Issue:10 "October 2020"

immensely find all the required information. Moreover, we exploited appealing images and drew some very enlightening conclusions of how to present them.

Picture 2: The vehicle of the Future based exclusively on solar energy

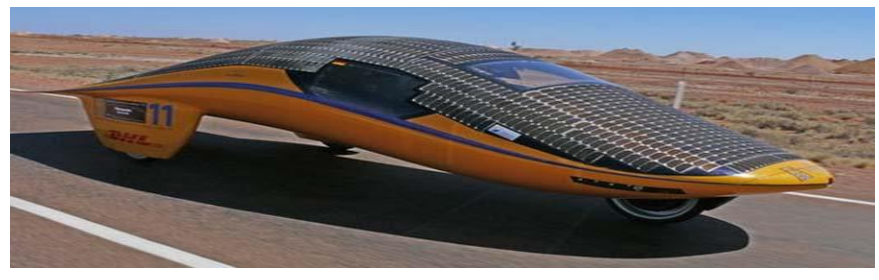

\section{Source: Renewable Energy World}

The same procedure was followed for the text selection; nevertheless, our decision was to resort to passages and texts in a quite restrained way, due to our firm belief that images capture our attendants' interest in juxtaposition to long and monotonous texts.

What is more, we preferred the various multimedia means not only for the purposes of a sheer presentation of our work - mainly through the use of the PowerPoint program, but also in order to achieve certain practical and communicational purposes, such synchronous and asynchronous interaction among the members of our team through the use of the Skype, Zoom and the Viber applications and through the email exchange.

In addition, we used a maquette (scale model) of photovoltaic contrived and fixed by ourselves, which would perfectly visualize the whole process of transforming solar into electrical energy. The maquette gave the students the chance not only to see and observe, but also to touch and realize how the entire energy generation system functions.

Actually this equipment consisted of Direct Current (DC) cables, Alternating Current (AC) cables, solar panels and of an aluminum construction where we placed the solar panels and some special plugs for the DC cables. Also we needed fuses for the DC and the AC cables.

Picture 3: The Maquette (Scale Model) showing the production of electricity out of the solar panels devised and constructed by the participating in the Microteaching Lesson students) 


\section{International Journal of Social Science and Economic Research}

ISSN: 2455-8834

Volume:05, Issue:10 "October 2020"

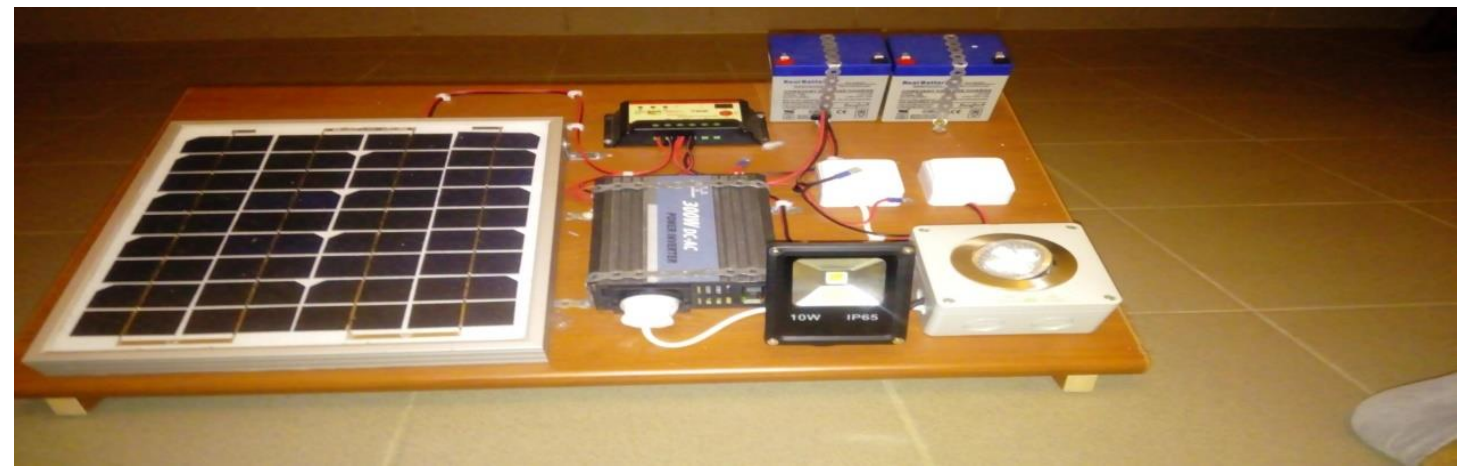

In order to get the best out of this procedure we decided to move on to the creation of a board game, played by following some simple rules. Our fellow students were requested to form two groups and play against each other: One player of the team throws the dice, moves accordingly his token on the board of the game and then the group is asked to answer a question on the solar panels. If their answer is correct, one credit is won. The winner of the game is the group that manages to reach the center of the board having won the most credits. All questions asked were based on our presentation, so that our fellow students could assimilate all the information in a more effective way.

Picture 4: The Board Game conceived by the participating in the Microteaching lesson students to enhance in a joyful way the comprehension of the work of solar panels.

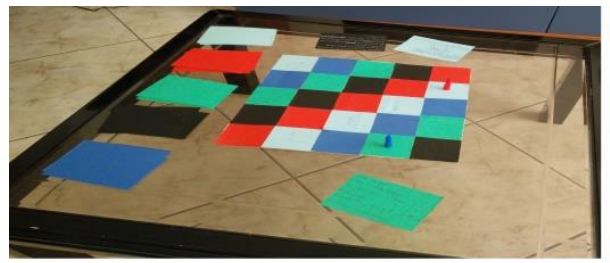

And that is exactly what our particular teaching techniques tried to accomplish: to give students information on a specific subject, then make sure that they have fully assimilated it and finally to encourage further, independent and deeper thinking and reflection. Our main target throughout our Microteaching was also to give students the opportunity to talk, to freely speak out views and ideas and to promote the so called "obstetric" teaching model, where all students are strongly encouraged to draw some conclusions by asking questions. This particular initiative differentiated, we believe, our teaching style from the traditional ones: we invited our classmates express their opinion, initiate a conversation, brainstorm, use their imagination to guess the meaning of unknown technical words and cooperate to solve the exercises that we had prepared 
for them. In the end, we handed them a questionnaire so that they could evaluate our presentation. The questions focused on the extent that our presentation succeeded in provoking the students' interest and on the width that our exercise and activities covered the subject efficiently.

We strongly believe that getting feedback from students is a very useful tool for the perpetual effort of accomplishing teaching improvement.

As a result, after having spent a lot of time for the assiduous preparation of our Microteaching, in the end we all shared the firm belief that we managed to introduce such a difficult subject - solar panels - by using an innovative and illustrative method of teaching both efficiently and in a pleasant way, boosting our own teaching skills and enhancing our fellow students' selfconfidence.

Last but not least, through the cooperation and the partitioning of the work we experienced the unique feeling of carrying out the objectives of a scheme and watching them come true. 